\title{
Literature Review of the Professional Farmers' Entrepreneurship Incubation Mechanism Based on Family Farms
}

\author{
Zhou Pan ${ }^{1, ~ *, ~ Y a n g ~ H u a n ~}{ }^{1}$, Chen Shengshuang ${ }^{2}$ \\ ${ }^{1}$ School of Economics and Business Administration, Central China Normal University, Wuhan, China \\ ${ }^{2}$ Department of Public Mathematics, Hankou College, Wuhan, China \\ Email address: \\ Zhoupan@163.com (Zhou Pan), Yanghuan@163.com (Yang Huan), ChenShengshuang@163.com (Chen Shengshuang) \\ *Corresponding author
}

To cite this article:

Zhou Pan, Yang Huan, Chen Shengshuang. Literature Review of the Professional Farmers' Entrepreneurship Incubation Mechanism Based on Family Farms. Social Sciences. Vol. 8, No. 6, 2019, pp. 354-363. doi: 10.11648/j.ss.20190806.18

Received: November 15, 2019; Accepted: December 4, 2019; Published: December 9, 2019

\begin{abstract}
In recent years, the traditional methods of production and management no longer meet the needs of agricultural development in the new era. Family farms, as an important carrier and a new type of business entity for the occupational peasant business incubation, have brought good economic and social benefits, and also pointed out the direction for China's agricultural modernization. This paper systematically reviews the literatures on the entrepreneurial incubator mechanism of professional farmers with family farms as carriers, and combs them into six aspects: entrepreneurship, farmer entrepreneurship, professional farmers, family farms, entrepreneurial environment and entrepreneurial incubation. Literature review, introduction of connotation and characteristics, clarification of development problems and countermeasures, combing the influencing factors, summarizing the definition of occupational farmers' entrepreneurial incubation mechanism. In the end, in order to improve the success rate of professional farmers' entrepreneurship incubation, we need to make corresponding adjustments or improvements in two aspects. From the perspective of external conditions, the government needs to provide good policy support, financial institutions innovate the rural financial system, vigorously develop rural infrastructure, to create a good entrepreneurial atmosphere. From the internal basis, professional farmers should start from their own, learn the skills required for entrepreneurship, create favorable conditions for the success of entrepreneurial incubation.
\end{abstract}

Keywords: Professional Farmers, Business Incubation, Family Farms

\section{Introduction}

In the process of agricultural modernization, China's agriculture has transformed from traditional small-scale agricultural production to large-scale, specialized and intensive production. Chinese farmers have also changed from "farmer status" to "professional farmers". As an important carrier of professional farmers' entrepreneurship incubation, family farms provide favorable conditions for the successful incubation of professional farmers. In the process of starting a business, the professional farmers have taken the family farm as the main business, which has greatly improved the production enthusiasm, created a good economic effect, and also brought great social effects. In 2012 and 2013, China's
Central No. 1 document successively proposed "strengthening new professional farmers" and "encouraging and supporting family farms". In 2017, Document No. 1 repeatedly mentioned vigorously cultivating new agricultural management entities. Therefore, the study of the family farms as the carrier of the professional farmers' entrepreneurial incubation mechanism is conducive to better support the occupational farmers' entrepreneurship, further promote the development of family farms to intensive, professional and moderate scale modern agriculture, promoting the transformation and upgrading of China's agricultural industry. The agricultural economy continues to grow.

Throughout the existing research on the theory of entrepreneurial incubation at home and abroad, most of the research focuses on high-tech industry incubator base and 
college students' entrepreneurial incubators. Most of the research target at high-tech talents and college students, and there is still rarely research on the career performance and incubation mechanism of professional farmers. There is a lack of in-depth systematic research on the professional farmer's entrepreneurial incubation mechanism based on family farms. Therefore, this paper systematically summarizes and reviews the professional farmer's entrepreneurial incubation mechanism based on family farms, from the aspects of entrepreneurship, farmer entrepreneurship, professional farmers, family farms, entrepreneurial environment and entrepreneurial incubation, by combing relevant literature at home and abroad. Further improve the theoretical system related to the incubation of entrepreneurial talents, in order to better cultivate the direction of professional farmers' entrepreneurship and guide the development of family farms.

\section{Main Body}

\subsection{Literature Review on Entrepreneurship}

In the early 18th century, the French economist Cantillon first officially proposed the concept of "entrepreneurship" [1]. After two and a half centuries of development and evolution, the definition of "entrepreneurship" is generally divided into narrow and broad senses. It refers to the creation of new enterprises, and the connotation of entrepreneurship in a broad sense is more abundant. At present, the academic community generally accepts the definition of entrepreneurship by Professor Stevenson of Harvard University (1985) [2], and believes that entrepreneurship is not limited by the limitations of current resource conditions. The process of capturing, utilizing, and developing opportunities and creating value. Some scholars have briefly summarized the definition of entrepreneurship. Drucker (1985) believes that entrepreneurship is to transfer resources from low-productivity to higher places [3]; Low (1988) simple define that creating new business is entrepreneurship [4].

For the definition of entrepreneurial functions, Knight (1921) believes that entrepreneurs are part of the uncertainty that can be dealt with at any time from the perspective of entrepreneurial competence [5]; Schumpeter (1934) points out the five aspects of innovation and points out Entrepreneurs must practice new combinations, break the original balance and achieve innovative destruction [6]. Gartner (1985) [7], Low, and MacMillan (1988), based on an in-depth study of entrepreneurship, believe that entrepreneurial entities are the founders of new ventures. Shane \& Venkataraman (2000) focuses on the entrepreneurial process and incorporates opportunities into the research of the entrepreneurial process, pointing out that the entrepreneurial process is the process of identifying, evaluating and developing entrepreneurial opportunities to create goods and services [8].

In the $21 \mathrm{st}$ century, the academic research on entrepreneurship has also heated up, and has obtained fruitful research results, mainly in three research themes. The first is the entrepreneurial subject, which aims to reveal the mechanism of the entrepreneur's traits, cognition and resource endowment on the entrepreneurial process. The second is the entrepreneurial opportunity to incorporate the identification and development of entrepreneurial opportunities into the research framework of the entrepreneurial process, and explore relevant correlations. The law has led to new concepts such as entrepreneurial vigilance and knowledge corridors; the third is the entrepreneurial environment, including the definition of the entrepreneurial environment, the division of dimensions and the mechanism that affects entrepreneurial behavior. The specific entrepreneurial development process and the theme of concern are shown in Table 1.

Table 1. Entrepreneurial development process and theme of concern. [9].

\begin{tabular}{|c|c|}
\hline Entrepreneur function & Cantillon(1775) Say(1826) Knight(1921) Schumpeter(1934) Hayek(1941) \\
\hline Entrepreneurial trait theory & McClelland(1961) Collins \& Moore(1964) Hornaday \& Aboud(1971) Brockhaus(1980) Hull et al.(1980) \\
\hline Focus on the entrepreneurial process & Gartner(1988) Low and Macmillan(1988) Bygrave \& Hofer(1991) Woo et al.(1994)..... \\
\hline Entrepreneurial nature & $\begin{array}{l}\text { Gartner(1985) Katz \& Gartner(1988) Gartner(1990) Stevenson \& Jarillo(1990) Gartner et al.(1992) } \\
\text { Bird(1992) Larson \& Starr(1993) Sarasvathy(2001) }\end{array}$ \\
\hline Endowment, process and performance & $\begin{array}{l}\text { Dubini \& Aldrich(1991) Hansen(1992) Cooper et al.(1994) Davidsson \& Honig(2003) Hoang \& } \\
\text { Antoncic(2003) Cope(2005) Baker \& Nelson(2005)...... }\end{array}$ \\
\hline Environment, strategy and performance & $\begin{array}{l}\text { Singh et al.(1986) Sandberg \& Hofer(1987) Romanelli(1989) Chandler \& Hanks(1994) McMullen \& } \\
\text { Shepherd(2006)..... }\end{array}$ \\
\hline Cognition, process and performance & $\begin{array}{l}\text { Shaver \& Scott(1991) Busenitz \& Barney(1997) Baron(1998,2004) Busenitz \& Alveraz(2001) Endres \& } \\
\text { Woods(2006)..... }\end{array}$ \\
\hline $\begin{array}{l}\text { Discipline independence exploration and } \\
\text { integration }\end{array}$ & $\begin{array}{l}\text { Shane \& Venkataraman(2000) Bruyat \& Julien(2001) Davidsson, low \& Weight(2001) Davidsson \& } \\
\text { Wiklund(2001) Gartner(2001) Ucbasaran et al.(2001) Busenitz et al.(2003) Van de ven(2004) Dean et } \\
\text { al.(2007)... }\end{array}$ \\
\hline Opportunity identification problem & $\begin{array}{l}\text { Aldrich\&Fiol(1994) Kirzner(1997) Shane(2000) Gaglio \& Katz(2001) Ardichivili et al.(2003) Carolis et } \\
\text { al.(2006) Alvarez \& Barney(2008)..... }\end{array}$ \\
\hline New business performance differences & Chandler et al.(2003) Delmar \& Shane(2004) Cassar(2006) Gilbert(2006) Gartner \& Liao(2006)..... \\
\hline
\end{tabular}

\subsection{Literature Review of Farmers' Entrepreneurship}

Early foreign research on rural entrepreneurship focused on promoting economic and development in rural areas. The economies of rural areas in some countries in Europe and America are still relatively backward, infrastructure construction and education have not kept up, and only relying on local agricultural and retail services. Employment 
opportunities cannot satisfy the surplus labor force, resulting in a large loss of labor to the city, which in turn exacerbates the development dilemma in rural areas. Therefore, solving the problem of economic development in rural areas has gradually become the research goal of the government and scholars. On this issue, Johnson (1989) pointed out that one of the ways is to develop local small and micro enterprises and promote the diversification of rural economy [10]. The government's duty is to strengthen local innovation and entrepreneurship education, so that more rural entrepreneurs can successfully establish new businesses to develop the local economy. Blanchflower (2000) first pointed out that tax policy has a positive effect on entrepreneurship [11]. Subsequently, Fonseca (2001) supplemented it [12]. He pointed out that the relevant policies and regulations issued by the government can affect entrepreneurs' entrepreneurial will and entrepreneurial behavior. Black \& Strahan (2002) pointed out that a sound credit market and financial support can promote the creation and growth of new businesses [13]. From the perspective of policy environment, Morris \& Drabenstott (1989) pointed out that the government should improve the policies in rural areas and provide a good financing environment for entrepreneurs in rural areas, thus stimulating entrepreneurial vitality [14].

For the difference between rural entrepreneurship and urban entrepreneurship, Stathopoulou et al. (2004) believe that although the process of rural entrepreneurship and urban entrepreneurship have little difference, the entrepreneurial opportunities and entrepreneurial environment faced by rural and urban areas are different, and the entrepreneurial process will be different, cause different effects eventually [15]. Compared with cities, rural areas have the characteristics of low population density, which is a risk and opportunity for entrepreneurs. On the one hand, rural areas have richer natural resources, which are entrepreneurial opportunities that are difficult to find in cities. On the other hand, the low population density makes access to conventional resources such as market size, channels, labor resources, and technology more difficult. Shields (2005) found that natural landscapes in rural areas can develop local tourism, thereby promoting local entrepreneurial enthusiasm [16]. Gladwin (1989) argues that the low market size in rural areas has led local companies to face greater bankruptcy risks than urban ones [17].

In addition to the characteristics of low population density, different environmental factors such as geographical location, natural resources, policy environment, market environment, cultural environment and infrastructure construction of rural entrepreneurial environment will have direct or indirect impact on rural entrepreneurial activities. For example, Skuras et al. (2000) found that infrastructure construction in rural areas directly affects entrepreneurs' willingness to go to the countryside to start a business [18]. Witbooi et al. (2011) pointed out that natural resources, technology and infrastructure have a positive impact on entrepreneurial performance through research on fruit-growing farmers in South Africa [19]. Chand (2011) believes that the cultural environment that tends to individualism can stimulate entrepreneurial enthusiasm [20]. It can be seen that for rural entrepreneurship, Western scholars pay more attention to the relationship between the rural environment and the entrepreneurial process. They believe that while the former provides entrepreneurial opportunities, it imposes resource constraints on the latter, thus affecting entrepreneurial behavior and ultimately the entrepreneurial performance.

Based on China's unique basic national conditions, the issue of farmers' entrepreneurship is closely related to solving the problem of "agriculture, rural areas and farmers". Therefore, domestic scholars have carried out a lot of related research on the phenomenon of farmers' entrepreneurship.

The first is the study of the characteristics of farmers' entrepreneurial areas. Guo Junying (2006) constructed the index of farmers' entrepreneurial activities, pointing out that the regional characteristics of farmers' entrepreneurship in China are internally consistent with the level of regional economic development, and the activity level in the eastern and western regions is obviously unbalanced [21]. Gu Jiajun and Xie Fenghua (2012) found that the influence of farmers' entrepreneurial activity on per capita income in various regions of China shows that the eastern region has a higher level of economic development, resulting in higher farmers' entrepreneurial rate than the western region, and farmers' entrepreneurship is positive [22]. To affect the average income of farmers. Scholars also focused on the situation and other characteristics of farmers' entrepreneurship. For example, Wang Xiyu et al. (2003) summarized the characteristics of returning migrant workers' entrepreneurship through questionnaire surveys of returning migrant workers across the country, including entrepreneurial characteristics, industry distribution and regional distribution [23]. Han Jun and Cui Chuanyi (2008) found that most of the initial start-up funds for migrant workers returning to their hometowns came from their own funds and faced difficulties in financing [24]. Liu Zhirong and Jiang Changyun (2008) reviewed the relevant literature and concluded that the reasons for the relatively low level of peasant entrepreneurship in the western region are mainly the shortage of funds [25], the overall low quality of labor, the inadequate government policies, and the need to optimize the entrepreneurial environment. In addition, the family-based organization of farmers when they start a business is too singular, which also restricts the improvement of entrepreneurial performance.

For the influencing factors of farmers' entrepreneurship, the existing research mainly focuses on four factors: individual characteristics, social network, resource endowment and entrepreneurial environment. For example, Zhu Honggen et al. (2010) used the binary logistic model to empirically analyze the factors affecting the entrepreneurial will of returning migrant workers in Jiangxi Province [26], and found that personal characteristics such as age, gender, marital status, and education level significantly affected their returning entrepreneurship. Willingness. On the basis of this, Shi Zhilei et al. (2010) found that participation in training and whether or not to go out to work also have an important impact on entrepreneurial will [27]. The study by Jiang Jianyong and Guo Hongdong (2012) found that farmers' entrepreneurial 
intentions are influenced by the entrepreneurial atmosphere [28], entrepreneurial role models and strong support in the network. In addition, as the core element of the entrepreneurial process theory, opportunity is the key content of scholars to study peasant entrepreneurship. Guo Hongdong and Zhou Huizhen (2013) proposed a mediating effect model of prior experience, entrepreneurial alertness and entrepreneurial opportunity identification [29]. It pointed out that prior work experience and previous training experience not only directly affect opportunity identification, but also verified that entrepreneurial alertness has Mediating Role. Based on 968 questionnaire data, Jiang Jianyong et al. (2014) pointed out that social network size and relationship intensity have a significant positive impact on entrepreneurial opportunity identification [30]. In addition, previous work experience and entrepreneurial experience can also improve the success rate of identifying entrepreneurial opportunities. As a stage to visually reflect and evaluate the degree of completion of entrepreneurship, entrepreneurial performance has naturally received a lot of attention from scholars to find ways to improve performance. Zhou Jinghua and Xie Zhou (2012) empirically analyzed the relationship between entrepreneurial ability and performance, pointing out that comprehensive entrepreneurial ability significantly affects farmers' family business income [31], that is, the improvement of entrepreneurial performance depends on the improvement of comprehensive entrepreneurship. Zou Fangfang and Huang Jie (2014) conducted empirical research on the relationship between entrepreneurial resources and entrepreneurial performance of different types and sources based on resource-based theory and venture capital theory, and found that they have their own social resources, resource financial resources and external financial resources. Significantly positively affects the entrepreneurial performance of returning migrant workers [32].

\subsection{Literature Review of Professional Farmers}

In the 1960s, American anthropologist Eric Wolf distinguished between traditional farmers and professional farmers in the book Farmers: "Peasant" was proposed to support livelihoods; and "Farmer" was dedicated in the industrialization of agriculture, improve the economic profits of the industry, and engage in agricultural production activities for life. Chinese scholar Zhao Xihua (2006) also distinguishes traditional peasants from new peasants [33]. He believes that new peasants is entrepreneurial peasants, they are peasants with entrepreneurial ability, adapted to market competition, and have market-oriented consciousness, highlights the "three transitions" ; the mode of operation changes from one household to large-scale operation; the social attribute changes from producer to operator; the status of civil law subject changes from natural person to enterprise legal person. Zhu Qizhen (2013) proposed three characteristics of professional farmers different from ordinary farmers [34]: "first, new professional farmers are the main players in the market, maximizing economic benefits is their main purpose, and second, relatively high stability, lifelong farming, and children succession career, the third is that the new professional peasant has a higher level of education and masters advanced technology and has a strong sense of social responsibility." Li Wenxue (2012) believes that professional peasants will develop in the future with high quality, high income and social respect [35]. Talk about the current situation, there are not many farmers in China who have fully met the "professional peasant" standard. As more and more farmers transfer land to expand production and management, most migrant workers return to their hometowns to engage in agricultural entrepreneurship. The ranks of farmers are also growing stronger. Family farms are the carrier of professional farmers, and professional farmers are the basis for the development of family farms. Mi Songhua et al. (2014) based on 495 survey data from four provinces, found that most of the professional farmers came from returning migrant workers, college students, large planters, farmers and entrepreneurs [36]. He believed that the focus of professional farmers is to cultivate good targets. the content of innovative training and enhanced incentives. Li Guoxiang and Yang Zhengzhou (2013) conducted research on American professional farmers, and on this basis put forward policy recommendations for China [37]. Shen Hongmei et al. (2014) conducted a research on the cultivation mechanism of emerging professional farmers in China based on the modern perspective. In recent years, new professional farmers have begun to enter the research field as an academic concept [38]. A series of discussions were held around the definition, type, education and training, dynamic mechanism and development model of new professional farmers, but research on the field of entrepreneurial performance and incubation mechanism of professional farmers is still rare.

\subsection{Literature Review on Family Farms}

Family farms originated in developed countries such as Europe and the United States, and foreign scholars have different research results on the relationship between farm scale and production efficiency. Bardhan (1973) found that there was a reverse correlation between farm size and productivity by studying family farms in Russia and India [39] Comia (1985) studied Peru and Thailand and found that there is a positive change in farm size and productivity [40]. A study by Cater \& Wiebe (1990) shows a "U" relationship between the two [41]. In addition, some scholars have found that when the farm is moderately sized, the production efficiency is the highest. The agricultural economist Schultz (1979)'s "inseparability rebuttal" theory and Sen's "IR law" study show that large-scale farm management does not bring higher efficiency, and moderate-scale family farms operate most efficiently Judge. However, under the high-tech level, Deolalikar et al. have shown that the "IR law" does not hold. In fact, the level of technology and scale of world agriculture is far less than the degree of industrialization. This situation is more obvious in China, which can also be used as a theoretical basis for the implementation of a modest scale of family farm model in China.

China's family farm research started late, Li Dongsheng 
(2000) believes that the large-scale operation of family farms must be regarded as an enterprise-oriented business entity, which requires scientific enterprise management methods to adapt farm produce to the market [42]. Gao Qiang (2013) proposed a new type of agricultural organization based on family production and management, using modern production factors and management concepts, and obtaining agricultural income sources to maintain intensive and commercial production and management [43]. Lang Xiuyun (2014) believes that family farms are family-owned, family members with the main labor force and a certain scale to meet market demand [44].

Regarding the characteristics of family farms, scholar Guo Xibao (2013) found that family farms have family management, family members are the main labor force, and they operate a certain scale and have long-term stable characteristics of farm income as an economic source [45]. Zhu Qizhen (2013) proposed that family farms also have the characteristics of industrial and commercial registration.

Regarding the development model of family farms, Lang Xiuyun (2013) summarized and compared family farms in France and Japan, and proposed to design and support household registration system, social security system and agricultural subsidy credit system [46]; He Jin et al (2014) from the United States and Japan The family farm management case concluded that China should establish a new farmland trading platform, plan rural land use, improve social services, and increase technology investment and government support [47]. Du Zhixiong and Xiao Weidong (2014) emphasized the importance of land use, government, education and intermediary services in the development of domestic family farms by studying family farms in five developed countries in Europe and America [48].

Questions about family farms and entrepreneurship. Domestic and foreign literature studies have shown the theoretical overlap between family farms, agriculture-related family businesses and entrepreneurship: Family Farms and agriculture-related families can be used as a unique organization form of entrepreneurship. Entrepreneurship is an indispensable link and stage strategy in the life cycle of family farms and family-owned enterprises. It runs through the growth trajectories of family farms and family-owned enterprises. The whole process. Family farms and agro-family families have "black boxes"in the mechanisms of entrepreneurial processes such as willingness to generate, opportunity identification, opportunity acquisition and initial performance. These need to be further explored.

\subsection{Literature Review on the Entrepreneurial Environment}

Throughout the study at home and abroad, many scholars have carried out fruitful research on the impact of the successful external environment of the entrepreneurial enterprise: mainly the American strategic management scientist Michael Porter proposed the diamond model in 1990, and then two Canadian scholars (Tim Padmore and Henrev Gibson) improved the diamond model and proposed the GEM model. The GEM model measures entrepreneurial environments from nine dimensions: financial support, government policy, government programs, education and training, research and development transfer, business environment, domestic market openness, infrastructure and intellectual property [49]. Cai Huahua (2008) divides the entrepreneurial environmental indicator system into internal environment, macro environment, market environment and natural environment [50]. Qian Zijian (2010) proposed to establish an evaluation index system for rural entrepreneurial environment, including economic support, service support, training support, cultural support and environmental support [51]. Xu Jin (2010) believes that building a financial support, entrepreneurship counseling, entrepreneurial opportunity integration and entrepreneurial services to form a relatively complete farmer returning entrepreneurship support system will help improve the success rate of migrant workers returning to their hometowns [52]. Qiao Rui (2011) combines the five-dimensional model and the global entrepreneurial observation model to combine the current situation of the domestic entrepreneurial environment with the research of the predecessors, and plans to establish an indicator system for the entrepreneurial environment of the migrant workers [53]. The system divides the entrepreneurial environment into economic foundation and government support. financial support, education and training, cultural environment, and resource supply. Xu Wen (2012) used empirical analysis to conduct on-the-spot investigations, and incorporated many influencing factors of migrant workers' returning hometown into the regression model for analysis, and constructed an entrepreneurial support system for migrant workers returning home [54]. Gu Yu (2013) proposed a comprehensive support system including policy support, financial support [55], entrepreneurial information services, entrepreneurship training and legal support based on the entrepreneurial strategy chosen by returning migrant workers to improve the external entrepreneurial environment and support returning farmers. Business entrepreneurship provides a good operational basis. Overall, the research on the career of entrepreneurs in China is not systematic.

Later, some scholars studied the impact of entrepreneurial environment on entrepreneurial performance. Zhu Honggen (2015) conducted a survey on farmers' entrepreneurship in Poyang Lake Ecological Economic Zone [56]. The results showed that financial service environment, social environment and infrastructure environment for farmers' entrepreneurship Performance has a significant impact. The policy support environment, entrepreneurial atmosphere environment and scientific and technological cultural environment have an indirect impact on farmers' entrepreneurial performance. The resource endowment environment has no significant impact on farmers' entrepreneurial performance. Bai Wenjing (2017) based on the sample of entrepreneurial farmers in Jilin Province [57], found that "financial services" and "humanities society" have significant effects on farmers' entrepreneurial performance, "economic development" and "infrastructure" influences are centered, "policy support" and "entrepreneurial education" 
"The impact is the weakest." The empirical research on entrepreneurial environment and farmers' entrepreneurial performance has also emerged in recent years.

Chi Renyong (2002) proposed that the business incubation system refers to the organic combination of infrastructure, policies and economic conditions necessary to incubate new concepts and technologies into enterprises [58]. He Peng (2014) conducted a research on the Cultural and Creative Park of Taiwan University [59]. He believes that the cultural and creative business incubator system is a combination of software and hardware, an entrepreneurial support integration system that not only provides the physical space necessary for cultural entrepreneurship, but also provides financing, talent support, and policy. Support a series of entrepreneurial services. In the agricultural field, the professional farmer entrepreneurship system can also be regarded as a system component that can transform a new concept and new technology into various external supporting environmental subjects through its systematic industrial operation. In this incubation process, the government, financial institutions, agriculture-related colleges, agricultural cooperatives, and entrepreneurial atmosphere included in the entrepreneurial environment may be conducive to promoting the incubation of professional farmers.

\subsection{Literature Review on Entrepreneurial Incubation}

For the behavioral process of entrepreneurial incubation, we must start with its carrier, the "incubator". The concept of incubator was first applied to the economic field by Joe Mancuso of the United States. After more than half a century, it gradually developed into entrepreneurial incubator and business incubator. In this process, many foreign scholars have conducted in-depth research from the definition, function, mode and performance of the incubator.

For the meaning of the incubator, the National Business Incubator Association (NBIA) defines it as a service-oriented business organization that provides entrepreneurial services to start-ups and supports entrepreneurial development. As early as 1985, Allen proposed that the incubator can be an interrelated organization network [60], providing a series of management and resource support for entrepreneurs or incubating enterprises, including venue facilities, related education and training, and business consulting services. On this basis, Rice (2002) believes that the incubator is responsible for the support of entrepreneurship, and the two have interdependent symbiotic relationships [61].

After clarifying the meaning of the incubator, foreign scholars began to focus on their main functions. Allen \& Rahman (1985) summarized the service functions of the incubator into five categories: space facilities, financing services, management support, professional business and general business [62]. At the same time, it pointed out that the incubator could not meet all the entrepreneurial needs of the incubating enterprises, but through external services. The network relationship established by the organization can play its own intermediary role. Smilor \& Gill (1986) pointed out that the core function of the incubator is to provide entrepreneurial service networks for entrepreneurs or incubators, and the scale [63], intensity and diversity of service networks will affect the possibility of entrepreneurs get opportunities. Lalkaka (1997) argues that providing the growth environment required by start-ups is the primary function of the incubator [64].

For the incubation mode and mechanism of the incubator, Campbell \& Kendrick described it as: the incubator to diagnose the market demand, cultivate the incubation company and monitor the process, and finally provide funds and networks for the enterprise through extensive cooperation [65]. On the basis of this, Smilor (1987) incorporated the incubator alliance, support system and internal incubator into the incubation framework, enriching the incubation mechanism of the incubator [66]. Hisrich (1988) believes that incubators are a system of continuous innovation by providing various incubation services to gather entrepreneurial talents and constructing corresponding innovation incentives. Finally [67], for the evaluation of incubator performance, foreign scholars mainly measure from three aspects: incubation success rate, business performance and potential, and transformation of technological achievements. For example, Rice (2002) pointed out that the proportion of successful incubators to the total enterprises can roughly reflect the performance of the incubator [61], while the incubation infrastructure, training service quality and incubation network can affect the performance. Rhonda (2002) pointed out that the efficiency of scientific and technological results transfer is a key indicator pursued by current incubators, although its performance in measuring performance is not good [68].

Domestic research on entrepreneurial incubation started late. The related research in the early stage was generally based on the reference to Western literature. Therefore, there are not many research results based on Chinese contexts on the definition and function of entrepreneurial incubator and incubator. In the two directions of the business incubation environment and the business incubation network.

Zhang Wei and Xing Wei (2007) believe that the entrepreneurial incubation environment includes policy support, cultural atmosphere, entrepreneurial network and infrastructure [69]. On this basis, the empirical research of Huang Yifang and Zhu Jiangyan (2009) shows that education and training also constitutes a business incubation [70]. An important element of the environment. In the agricultural field, Huang Shaoan (2003) pointed out that land, household registration and education system are the three major environmental factors that affect farmers' entrepreneurship in China [71]. Luo Xinyang (2009) based on the GEM model and factor combination model, and related to the rural situation in China [72], divided the rural entrepreneurial environment into five sub-systems of economy, training and environment, and designed the corresponding evaluation index system. Zhang Xiuyan et al. (2010) revised the GEM model and pointed out that there are three aspects that affect the environmental factors of migrant workers returning to their hometowns: external environment, personal traits and previous work experience. As for the impact of 
entrepreneurial environment on farmers' entrepreneurial activities [73], Zhu Honggen et al. (2011) conducted a survey of 1145 returning migrant workers in Jiangxi Province, they pointed out that environmental factors such as policy support, infrastructure construction, and venture capital environment significantly affected migrant workers returning home [74]. The willingness to start a business is also positively related to entrepreneurial performance. Wang Yushuai and $\mathrm{Wu}$ Chao (2013) summarized the government's support policy system into five aspects: policies and regulations, finance, culture, education and training, and skills services, which together constitute the policy environment and thus affect farmers' entrepreneurial will [75].

The domestic academic community has also carried out many explorations on the research of the entrepreneurial incubation network. Jiang Renguo et al. (2011) summarized the production methods of the incubation network into spatial expansion, cooperation extension, and technical interaction [76]. Tan Kaiming and Wei Shihong (2007) based on the networked history of incubators, pointed out that the government supports networks, human resources networks, knowledge networks, supply chain relationships and other social support networks that constitute incubators [77]. After studying the construction mechanism of the incubation network, Zhang Wei and Li Jia (2008) pointed out that the incubation function mainly focuses on the initial stage and development period of the enterprise, and provides entrepreneurial services including four aspects of demand diagnosis, supervision, financing and network support [78]. Yu Xiaodan et al. (2009) explained that the service process of the business incubator network is the process in which the incubating enterprise obtains resources and applies it to innovative activities through government departments, universities, scientific research institutions, intermediaries and other actors [79]. Zhang Weiguo et al. (2006) discussed the relationship between collaboration and game among various subjects in the incubation network [80].

\section{Conclusion}

The success of entrepreneurial incubation is a process in which a variety of factors work together. The successful incubation of professional farmers is not only affected by the external environment, but also by subjective factors. Therefore, the occupational peasant incubator mechanism is the process of interaction and mutual influence between the external support system such as the infrastructure, government policies and economic conditions required by the professional peasant entrepreneurship and the professional peasants' previous experience, learning communication and resource integration ability. From the existing research literature, the lack of systematic and in-depth study on the career farmer incubation mechanism based on family farms has not comprehensively summarized the interrelationship and function system of professional farmers' entrepreneurial incubation mechanism, which can be discussed in the future research.
This paper focuses on six aspects of entrepreneurship, farmer entrepreneurship, professional farmers, family farms, entrepreneurial environment and entrepreneurial incubation, analyzes its definition, types and characteristics, summarizes relevant theories, and builds a structural system. From connotation to extension, systematically summarize and comment on the career farmer incubation mechanism based on family farms. To improve the success rate of professional farmers' entrepreneurship incubation, it is necessary to make corresponding adjustments or improvements in two aspects. From the perspective of external conditions, the government needs to provide good policy support, financial innovation in the rural financial system, and secondly to vigorously develop rural infrastructure to create a good entrepreneurial atmosphere. From the internal basis, professional farmers should start from their own, learn the skills required for entrepreneurship, and create favorable conditions for the success of entrepreneurial incubation.

\section{References}

[1] Cantillon R. Essai sur la Nature du Commerce en General, (An Essay on the Nature of business in General), circa 1730, Edited and translated by Henry Higgs, London: Frank Cass, 1959.

[2] Stevenson H. H. and Gumpert D. E. The heart of entrepreneurship. Harvard Business Review, 1985, 85 (2): 85-94.

[3] Drucker P. F. Innovation and Entrepreneurship, New York: Harper\& Row, 1985.

[4] Low M. B. and Macmillan I. C. Entrepreneurship: Past Research and Future Challenge. Journal of Management. 1988, 14 (2): 139-161.

[5] Knight F. H. Risk, Uncertainty and Profit. Boston, MA: Hart, Schaffner and Marx, Houghton Mifflin Company, 1921.

[6] Schumpeter J. A. The Theory of Economic Development Cambridge. MA: Harvard University Press, 1934.

[7] Gartner W. B. A Conceptual Framework for Describing the Phenomenon of New Venture Creation. Academy of Management Review, 1985, 10 (4): 696-707.

[8] Shane S. and Venkataraman S. The Promise of Entrepreneurship as a Field of Research. Academy of Management Review, 2000, 25 (1): 217-226.

[9] Wei Xufang. Farmers' Entrepreneurship: Resources, Performance and Models, People's Publishing House, 2016, p. 23.

[10] Johnson T. G. The Role of Entrepreneurship in Rural Economic Development. Congressional Research Service Symposium entitled" Towards Rural Development Policy for the 1990s: Enhancing Income and Employment Opportunities. 1989.

[11] Blanchflower D. G. Self-employment in OECD Countries. Labor Economics, 2000, 7 (5): 471-505.

[12] Fonseca R. E. Entrepreneurship: Start-up and Employment, European Economic Review, 2001, vol. 4-6: 692-705.

[13] Black S. E. and Strahan P. E. Entrepreneurship and bank credit availability. Journal of Finance, 2002, 57 (6): 2807-2833. 
[14] Morris C. and Drabenstott M. Financing rural businesses: What role for public policy?. Economic Review, 1989: 30-45.

[15] Stathopoulou S., Skuras D. and Psaltopoulos D. Rural entrepreneurship in Europe: A research framework and agenda. Social Science Electronic Publishing, 2004, vol. 10 (6): 404-425.

[16] Shields J. F. Does Rural Location Matter? the Significance of a Rural Setting for Small Businesses. Journal of Developmental Entrepreneurship, 2005, 10 (1): 49-63.

[17] Gladwin C. H., Long B. F. and Babb E. M. et al. Rural entrepreneurship: One key to rural revitalization. American Journal of Agricultural Economics, 1989, 71 (5): 1305-1314.

[18] Skuras D., Dimara E. and Vakrou A. The Day after Grant-aid: Business Development Scheme for Small Rural Firms in Lagging Areas of Greece, Small Business Economics, 2000, 14 (2): 125-136.

[19] Witbooi M., Cupido C. and Ukpere W. I. Success Factors of Entrepreneurial Activity in the Overberg Region of Western Cape, South Africa. African Journal of Agriculture Research, 2011, 4 (5): 1936-1941.

[20] Chand M. The Need for Indigenous Social Entrepreneurial Spirit in the Sugar Industry Growth and Development in Fiji, Strategies and Innovations for Sustainable Organization, 2011, vol. 6: 620-638.

[21] Guo Junying. Research on Regional Differences of Farmers' Entrepreneurship in China. Economic Problems Research, 2006 (6): 70-74.

[22] Gu Jiajun, Xie Fenghua. Analysis of Regional Differences in Farmers' Entrepreneurial Activity Affecting Farmers' Income-An Empirical Study Based on Provincial Panel Data from 1997 to 2009. Agriculture Economics, 2012 (2): 21-25.

[23] Wang Xiyu, Cui Chuanyi, Zhao Yang. Working and Returning to Hometown: Employment Transformation and Rural Development_ A Study on Partial Urban Migrant Workers Returning to Hometown for Entrepreneurship. Management World, 2003 (7): 99-109.

[24] Han Jun, Cui Chuanyi. The Difficulties and Countermeasures of Migrant Workers Returning to Hometown in China. Economic Survey, 2008 (11): 3-8.

[25] Liu Zhirong, Jiang Changyun. A Literature Review on the Development of Farmers' Entrepreneurship - focusing on Farmers' Entrepreneurship in Western Regions. Research Economic Research, 2008 (66): 37-47.

[26] Zhu Honggen, Kang Lanyuan, Weng Yulin, Liu Xiaochun. An Empirical Analysis of the Influencing Factors of Migrant Workers' Willingness to Return to Hometown in Labor Export Province_-Based on Survey Data of 1145 Returned Migrant Workers in Jiangxi Province. China Rural Observation, 2010 (05): 38-47.

[27] Shi Zhilei, Tan Yu, Wu Haitao. Analysis of entrepreneurial behavior and entrepreneurial willingness of returning migrant workers. China Rural Watch, 2010 (05): 25-37+47.

[28] Jiang Jianyong, Guo Hongdong. Entrepreneurial atmosphere, social network and farmers' entrepreneurial intentions. China Rural Watch, 2012 (2): 20-27.
[29] Guo Hongdong, Zhou Huizhen. Prior Experience, Entrepreneurship Alert and Farmers' Entrepreneurial Opportunity Recognition_-A Mediating Effect Model and Its Enlightenment. Journal of Zhejiang University: Humanities and Social Sciences, 2013, 43 (4): 17-27.

[30] Jiang Jianyong, Qian Wenrong, Guo Hongdong. A Study on the Influencing Factors of Farmers' Entrepreneurial Opportunity Recognition_-Based on a Survey of 968 Questionnaires. Journal of Nanjing Agricultural University (Social Science Edition), 2014 (1): 51-58.

[31] Zhou Jinghua, Xie Zhou. Study on the relationship between farmers' entrepreneurial ability and entrepreneurial performance-Based on the survey data of 366 entrepreneurial farmers in Chongqing. Agricultural Technology and Economy, 2012 (05): 121-126.

[32] Zou Fangfang, Huang Jie. The Impact of Entrepreneurial Resources of Returned Migrant Workers on Entrepreneurial Performance. Agricultural Technology and Economy, 2014 (4): 80-88.

[33] Zhao Xihua, Zhou Yidong. Analysis of the status quo, influencing factors and countermeasures of farmers' entrepreneurship. Jianghai Academic Journal, 2006 (01): 217-222.

[34] Zhu Qizhen. New Professional Farmers and Family Farms. Journal of China Agricultural University (Social Science Edition), 2013, 30 (02): 157-159.

[35] Li Wenxue. New professional farmers must have four characteristics. Rural Work Communication, 2012 (07): 35.

[36] Zhu Qiwei, Mi Songhua, Huang Lili, Huang Hexiao. Study on the Willingness and Influencing Factors of New Type of Professional Farmers Participating in Skills Training —_An Empirical Analysis Based on Scale Farmers. Zhejiang Journal of Agricultural Sciences, 2014, 26 (05): 1361-1367.

[37] Li Guoxiang, Yang Zhengzhou. The policy of cultivating new professional farmers in the United States and its enlightenment. Agricultural Economic Issues, 2013, 34 (05): 93-97 112.

[38] Shen Hongmei. The Ecological Dilemma and Path Choice of Modern Agricultural Development in China_-Based on the Perspective of Ecological Socialism. Reform and Strategy, 2014, 30 (07): 67-70.

[39] Bardhan P. K. Size, Productivity and Returns to Scale: An Analysis of Farm Level Date in Indian Agriculture [J]. Journal of Political Economy, 1973, 81 (6) 1370-1386.

[40] Cornia G. A. Farm Size, Land Yields and the Agricultural Production Function: An Analysis for Fifteen Developing Countries [J]. World Development, 1985, 13 (4): 513-534.

[41] Carter M. and Wiebe K. Access to Capital and its Impact on Agrarian Structure and Productivity in Kenya [J]. American Journal of Agricultural Economics, 1990, 72 (5): 1146-1150.

[42] Li Dongsheng, Zeng Lingxiang, Zha Jinxiang. The Status Quo and Countermeasures of Family Farm Development in China [N]. Journal of Fujian Agricultural University (Social Science Edition), 2000, 3 (3): 5-8.

[43] Gao Qiang, Liu Tongshan, Kong Xiangzhi. Institutional Analysis of Family Farms: Characteristics, Mechanisms and Effects. Economist, 2013 (6): 48-56. 
[44] Lang Xiuyun. Family farm: A new market subject dominating modern agriculture in China [J]. Journal of Hunan agricultural university (social science edition), 2014, 15 (06): 1-6.

[45] Guo Xibao. Family farm is the main body of agricultural scale operation [N]. Hubei daily, 2013-03-04 (015).

[46] Lang Xiuyun. Family farm: International experience and enlightenment - A case study of the development of family farm in France and Japan [J]. Mao Zedong Deng Xiaoping theory research, 2013 (10): 36-41+91.

[47] He jin, Xiong xueping, Song jintian. Comparison of foreign family farm model and development path selection in China [J] Economic aspect, 2014 (08): 103-106.

[48] Du zhixiong, Xiao weidong. Practical status and policy support of family farm development: Based on international experience [J]. Reform, 2014 (06): 39-51.

[49] Gao Jian et al. Global Entrepreneurship Watch China Report Based on the analysis of 2005 data. Beijing: Tsinghua University Press, 2006.

[50] Cai Zhuanghua, Yang Xuhui, Li Yaowei. Construction of the Index System for Entrepreneurial Environmental Assessment. Business Times, 2008 (34): 51-52.

[51] Qian Zijian, Luo Xinyang. An Empirical Study of Rural Entrepreneurial Environment: Taking Shaoxing, Zhejiang as an Example. Northern Economy, 2010 (2): 28-30.

[52] Xu Jin, Luo Jianyan. Research on the Construction of Migrant Workers' Returning to Hometown Entrepreneurship Support System Based on SWOT Model— - Taking Zhejiang Province as an Example. Tianfu New Theory, 2010 (06): 92-96.

[53] Qiao Rui, Wei Feng. Research on the Construction of Entrepreneur's Entrepreneurship Environment Evaluation System: Based on Analytic Hierarchy Process and Fuzzy Evaluation Method. Modern Trade and Industry, 2011 (6): 33-34.

[54] Xu Wen. Research on the problem of migrant workers returning to their hometowns-Taking Hunan Province as an example. Hunan Agricultural University, 2012.

[55] $\mathrm{Gu} \mathrm{Yu}$. Research on the entrepreneurial support system for migrant workers returning from Xiangyang City. Inner Mongolia Agricultural University, 2013.

[56] Zhu Honggen, Liu Lei, Kang Lanyuan. Research on the Impact of Entrepreneurial Environment on Farmers' Entrepreneurial Performance. Agricultural Economics and Management, 2015 (01): 15-25.

[57] Bai Wenjing. Analysis of Environmental Factors of Farmers' Entrepreneurship Performance in Jilin Province. Cooperative Economy and Technology, 2017 (09): 74-77.

[58] Chi Renyong. A Comparative Study of American and Japanese Entrepreneurial Environments. Foreign Economics and Management, 2002 (9): 13-19.

[59] He Peng, Zhuang Xiaolan. Discussion on Constructing the Incubation System of Fujian University Students' Cultural and Creative Enterprises. Management Observation, 2014 (28): 139-142.

[60] Allen D. N. and Rahman S. Small business incubators: A positive environment for entrepreneurship. Journal of Small Business Management, 1985, 23 (3): 12-22.
[61] Rice M. P., Co-production of business assistance in business incubators: An exploratory study. Journal of Business Venturing, 2002, vol. 17: 163-187.

[62] Allen, D., \& Rahman, S., 1985. Small business incubators: a positive environment for entrepreneurship. Jourmal of Small Business Management, 23 (3): 12-22.

[63] Smilor R. W. and Gill M. D. The new business incubator: linking talent, technology, capital, and know-how. Lexington, MA: Lexington Books, 1986.

[64] Lalkaka R. Lessons from international experience for the promotion of business incubator systems in emerging economies: Number3[M]. New York: Business and Technology Development Strategies. 1997.

[65] Campbell C., Kendrick R. C. and Samuelson D. S. Stalking the latent entrepreneur: business incubators and economic development. Economic Development Review, 1985, 3 (2): $43-49$.

[66] Smilor R. W. Commercializing technology through new business incubators. Research Management, 1987, 30 (5): 36-41.

[67] Hisrich R. D. and Smilor R. W. The university and business incubation: Technology transfer through entrepreneurial development. The Journal of Technology Transfer, 1988, 13 (1): 14-19.

[68] Rhonda G. P. Technology business incubators: How effective as technology transfer mechanisms? Technology in Society, 2002, vol. 24: 299-316.

[69] Zhang Wei, Xing Wei. Research on the Relationship between Entrepreneurial Incubation Environment and Growth Performance of High-tech Enterprises. Science Research, 2007 (01): 74-78.

[70] Huang Yifang, Zhu Jiangyan. An Empirical Study on the Elements of Entrepreneurial Incubation Environment Based on Entrepreneur Cognition. Enterprise Economy, 2009 (05): 64-67.

[71] Huang Shaoan. Institutional Analysis Restricting Farmers' Getting Rich. Academic Monthly, 2003 (6): 96-102.

[72] Luo Xinyang. Research on Rural Entrepreneurship Environmental Assessment System. Journal of Bingtuan Party School, 2009 (2): 66-69.

[73] Zhang Xiuyan, Zhang Zheng, Liu Yang. Analysis of factors influencing the entrepreneurial activities of returning migrant workers based on the GEM revised model. Social Science Front, 2010 (7): 65-70.

[74] Zhu Honggen, Weng Yulin, Chen Zhaoqi. An Empirical Analysis of the Impact of Policy Support on Migrant Workers Returning to Hometowns_—Based on Jiangxi Survey Data. Journal of Jiangxi Agricultural University (Social Science Edition), 2011, 10 (01): 19-27.

[75] Wang Yushuai, Wu Chao. The construction and support system of the theoretical framework for migrant workers returning to their hometowns. Corporate Economy, 2013 (9): 150-155.

[76] Jiang Renguo, Zhang Wei, Zhang Baojian. A Review of Research on Networking Mechanism of Business Incubator Organization. Exploration of Economic Issues, 2011 (05): 80-84. 
[77] Tan Kaiming, Wei Shihong. The Evolution and Enlightenment of the US Technology Incubator Network. Science and Technology Management Research, 2007 (04): 58-59+62.

[78] Zhang Wei, Li Jia. Research on the Operation Mechanism of Social Network Entrepreneurship Mode of Technology Business Incubator-Taking Xi'an High-tech Zone Entrepreneurship Service Center as an Example. Science and Technology Progress and Countermeasures, 2008, 25 (12): 18-21.
[79] Yu Xiaodan, Wang Keyi, Zhong Qi. Research on Business Incubator Knowledge Network and Its Innovation Mechanism. Technology and Management, 2009, 11 (06): 56-59.

[80] Zhang Weiguo, Chen Xuemei, Chen Yu. Discussion on the boundary problem of non-equity strategic alliances. Science and technology progress and countermeasures, 2006 (04): 136-138. 